Research Article

\title{
Experimental Investigation of a Novel Extracting Water System from Air by Soil Cold Source
}

\author{
Jianan Yao $\mathbb{D}^{1,2,3}$ Xingtian Wang ${ }^{1 D},{ }^{1,2}$ Junfeng $\mathrm{Zhu}^{1,2}$ Binbin Wang, ${ }^{4}$ and Junkui Niu ${ }^{1,2}$ \\ ${ }^{1}$ Yinshanbeilu Grassland Ecohydrology National Observation and Research Station, \\ China Institute of Water Resources and Hydropower Research, Beijing 100038, China \\ ${ }^{2}$ Institute of Water Resources for Pastoral Area Ministry of Water Resources, Hohhot 010020, Inner Mongolia, China \\ ${ }^{3}$ College of Science, Inner Mongolia University of Technology, Hohhot, China \\ ${ }^{4}$ Inner Mongolia Institute of Metrology and Testing, Hohhot 010010, China
}

Correspondence should be addressed to Xingtian Wang; wangxingtian525@qq.com

Received 7 May 2021; Accepted 12 November 2021; Published 28 November 2021

Academic Editor: Mostafa S. Shadloo

Copyright (c) 2021 Jianan Yao et al. This is an open access article distributed under the Creative Commons Attribution License, which permits unrestricted use, distribution, and reproduction in any medium, provided the original work is properly cited.

The distribution of fresh water resources is extremely uneven at home and abroad, and the air contains a large amount of water vapor that can be used, so air water has been a widespread concern. Air condensation method is simple and efficient and has strong water intake capacity, but it often needs to consume huge energy. Therefore, this work proposes a new simple and innovative method of drawing water from the air, based on extracting water from air process achieved by using the soil as the cold source. The new type of ground cold air water intake system is designed by the new innovative method, which uses the soil with constant temperature as the cold source to reduce energy consumption. By comparing the central composite design experiment with the field experiment and analyzing the condensate water and outlet temperature under different wind speed and humidity conditions, the quadratic equation expression of condensate water and outlet temperature is obtained, and the optimal import wind speed range under a certain humidity range is obtained according to the mathematical model. The experimental results show that the heat transfer effect between air and soil is ideal, the water intake can reach $2.2 \mathrm{~kg}$ in 20 -hour continuous collection experiment, the air temperature is close to the soil temperature after cooling, and the effect of water intake is good, which confirms the feasibility of soil as a cold source of air condensation.

\section{Introduction}

For a long time, the spatial distribution of freshwater resources at home and abroad is extremely uneven [1]. Many countries, mostly in the developing world, are either experiencing physical or economic water scarcity or are approaching physical water scarcity [2]. According to WHO and UNICEF's Joint Monitoring Programme (JMP) of the Millennium Development Goals (MDG), 663 million people still lacked improved drinking water sources in 2015 [3]. Our country is a country having a serious shortage of water. The total fresh water of our country is 2800 billion cubic meters, accounting for $6 \%$ of the world's total fresh water, taking the fourth place [4]. The problem of providing arid areas with fresh water can be solved by the following methods: (1) transportation of water from other locations, (2) desalination of saline water (ground and underground), and (3) extraction of water from atmospheric air [5]. Transportation of water through these regions is usually very expensive, and desalination depends on the presence of saline water resources, which are usually rare in arid regions [6].

The atmosphere is rich in water resources, even in extremely arid desert areas, the water content in the air can reach $10 \mathrm{~g} / \mathrm{m}^{3}$, and according to the estimates, the water vapor content in the atmosphere can reach more than 10 times the total amount of surface freshwater [7]. At the same time, the use of certain specific technologies can capture moisture in the air, which is not limited by the region, can be widely used in islands, deserts, and other areas, and can also be used in the field, combat, and other occasions, with strong 
applicability, so it has become a hot topic of extensive research at home and abroad. Extraction of water from atmospheric air can be accomplished by three different methods [8], and the currently commonly used technologies are air cooling condensation method [9], adsorption desorption method [10], water mist intake method, and so on [11].

Although the structure of water mist intake method is simple and does not involve the phase change process of water in the use process, it requires a higher environment for use and can often be applied in dense fog prone areas [12]. Adsorption water intake method is the most convenient; the equipment is often small so that it is easy to carry, but it also leads to small water intake, so it is often suitable for some emergency situations such as the field [13]. Currently, manufacturers like SunToWater Technologies [14] and Aqua Sciences [15] have invested a lot of money to develop air extraction aquatic products. These systems are especially suited to areas with high temperatures and humidity levels that increase the water yield due to the increased water content of air [16].

In contrast, the method of air condensation is extracting water from humid air by reducing the temperature of the air below its dew point [17]. It is the simplest most efficient method that uses no compressor, no reduction in the risk of failure, no refrigerant, and no pollution. It has low maintenance demand, low cost, and stable operation [18] and has a strong capacity of water intake, which is mostly used in some densely populated arid areas, but its cold source is difficult to find and often requires huge energy consumption in the process of condensation [19].

\section{Objective and Novelty of the Project}

Research endeavors linking innovation to the wider challenges of looming water-shortage can contribute to generating additional insights for speeding up water innovation uptake [20]. This study presents a new simple and innovative method of drawing water from the air. The new water collection system is based on the condensation process achieved by using the soil as the cold source.

The designed system involves a simple construction with low costs, realizable on-site, and reduced environmental impact [21]. It is also a simple alternative to condenser and adsorbent units currently on the market, in terms of cost, ease of installation, and maintenance [22]. As the scientific and industrial community is increasingly interested in low energy consumption and no pollution [23], the proposed system can be considered in line with this trend [24], and the system has low energy consumption and can be operated with a small amount of energy produced by wind and solar energy, so it can be widely used in the wild and remote areas not connected to the grid [25].
In this paper, the characteristics of condensate water and outlet temperature under different wind speed and humidity conditions were studied. An original mathematical model of condensate flow rate and outlet temperature is proposed. The influence of the outlet temperature on the condensate water quantity is studied and analyzed through the contrast experiment. The purpose of this work is to demonstrate the feasibility of soil as a source of air condensation. And the energy consumption of the air condensation process can be reduced to a certain extent.

\section{Laboratory Experiment}

In order to confirm the feasibility of using soil as a cold source for air extraction, we built an experimental system in the laboratory and used a central composite experimental design method for experimental validation to evaluate the nonlinear relationship between wind speed and humidity and the corresponding condensate volume and outlet temperature to provide a theoretical basis for wild tests.

3.1. Experimental Principle and Method. The experimental system is shown in Figure 1. Types and basic parameters of heat exchange tube are listed in Table 1 . To ensure that the state of the air is not altered before it enters the condensing unit, the experimental system uses a silicone hose with an insulating cotton outer wall to connect the constant temperature and humidity chamber to the condensing unit. The end of the outlet line is placed in a beaker and the amount of water condensed is recorded in real time using a meter device. Temperature and humidity sensors are installed in the inlet and outlet air lines to collect temperature and humidity data from the inlet and outlet air to monitor the heat transfer in real time.

The experiment uses the fan in the constant temperature and humidity box to send the air in the box through the inlet air line to the condensing unit and to carry out heat exchange. When the air temperature drops below the dew point through the heat exchange, the water vapor begins to undergo a phase change and condenses into liquid water on the inner wall of the condensing unit, which flows out along the wall of the condensing unit under the action of gravity and airflow. The condensate flows out along spiral corrugated condenser tube by gravity and airflow and eventually flows into a beaker on an electronic balance, which records the amount of condensed water in real time.

Because of the large range of wind speed in the experiment, the available energy loss rate analysis is used to evaluate the comprehensive performance of the flow heat transfer process effectively, which is used as an index to measure the performance of the process and calculate the wind speed range with high heat transfer efficiency.

Calculation formula of available energy loss rate is as follows: 


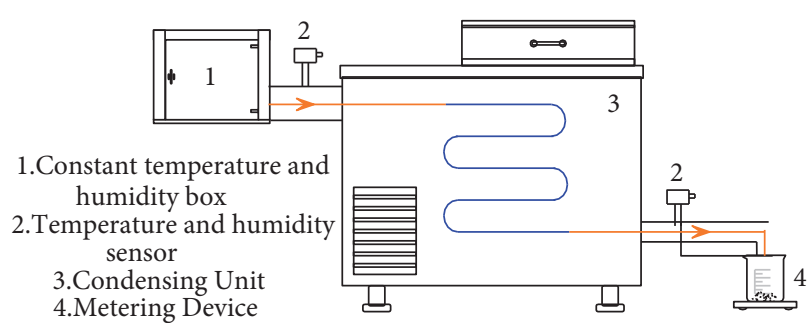

(a)

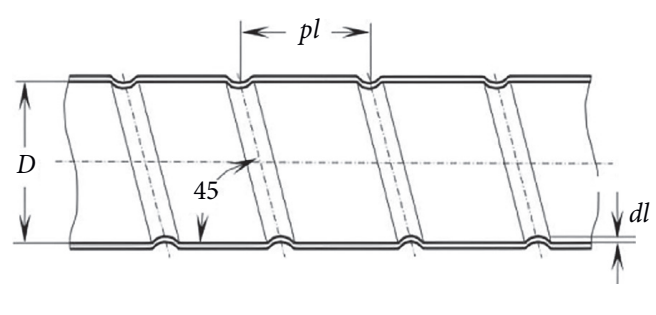

(b)

Figure 1: The experimental device and structural drawing of spiral corrugated condenser tube. (a) Experimental device diagram. (b) Structural drawing of spiral corrugated condenser tube.

TABLE 1: Types and basic parameters of spiral corrugated condenser tube.

Type of heat exchange tube Thread diameter (di) (mm) Thread spacing (p) (mm) Thread inclination $(\alpha)$ Thread depth (e) (mm)

\begin{tabular}{lllll}
\hline Spiral fluted tube & 10 & 12 & $45^{\circ}$ & 0.3 \\
\hline
\end{tabular}

$$
\mathrm{Ne}=6.4375 \frac{q L}{\lambda T_{m}} \operatorname{Re}^{-0.8222}\left(\frac{e}{d_{i}}\right)^{-0.39996}\left(\frac{p}{d_{i}}\right)^{0.11507} \operatorname{Pr}^{-1 / 3}+4.4161 \frac{\rho v^{3}}{q L^{3}} \operatorname{Re}^{2.8181}\left(\frac{e}{d_{i}}\right)^{1.7273}\left(\frac{p}{d_{i}}\right)^{-1.4916} .
$$

The formula for calculating the optimum Reynolds number with the minimum loss rate of available energy is as follows:

$$
\operatorname{Re}_{\mathrm{opt}}=0.7858\left[\frac{q^{2} L^{4}}{\lambda T_{m} \rho \nu^{3}\left(e / d_{i}\right)^{2.12726}\left(p / d_{i}\right)^{-1.60667} \operatorname{Pr}^{1 / 3}}\right]^{0.2747}
$$

According to calculation, the loss rate of available energy of $10 \mathrm{~mm}$ diameter spirally fluted tube must be less than the optimal Reynolds number 25000 in order to achieve the application purpose of high heat transfer rate and low loss rate of available energy. Therefore, according to the calculation results, the optimal Reynolds number is $8000-25000$, corresponding to the wind speed of pipeline $11-35 \mathrm{~m} / \mathrm{s}$.

Therefore, the wind speed range of $11-35 \mathrm{~m} / \mathrm{s}$ in the test is set as the wind speed range to meet the higher performance of unit heat transfer. According to the average humidity range in summer in the north of China, the specific humidity range of the inlet air is set as $6-14 \mathrm{~g} / \mathrm{kg}$, and the temperature of the inlet air is kept at room temperature $24.5^{\circ} \mathrm{C}$ through a constant temperature wet air supply silo in order to make the heat transfer effect under different conditions comparable.

The power of the humidifier is automatically adjusted by the single-chip microcomputer module to ensure the constant set specific humidity. According to the principle that the lowest dew point temperature is slightly higher than the outer wall temperature of the condenser within the specific humidity range, the temperature of the thermostatic chamber where the condenser is located is set to $4^{\circ} \mathrm{C}$, so as to ensure that condensed water is still generated under the lowest specific humidity condition, and the test results of each level are comparable.
In order to make the result of the condensed water volume have reference, the air volume in the test is set to be constant $20 \mathrm{~m}^{3}$, so the test time is different under the conditions corresponding to different wind speeds, and the specific settings are shown in Table 2.

3.2. Results and Discussion of Single Factor Experiment. By adjusting the fan power to carry out constant air volume experiment, the influence of different air velocity on heat transfer efficiency and the amount of condensate water produced under different humidity conditions is tested.

As shown in Figure 2, with the decrease of specific humidity, the amount of condensed water will decrease, and the lower the specific humidity, the more significant the downward trend of condensed water. With the increase of wind speed, the amount of condensed water decreased obviously, and the amount of condensed water was the largest at the lowest wind speed. Under the condition of high specific humidity, with the increase of wind speed, the change of condensed water volume is relatively smooth, while with the decrease of specific humidity and the increase of wind speed, the change of condensed water volume is relatively steep.

The results show that, in order to obtain more condensate water, the lower the specific humidity, the narrower the corresponding optimal wind speed range, while in the case of high specific humidity, the optimal wind speed range is larger.

By adjusting the inlet air velocity, the outlet temperature was tested under different specific humidity conditions. As shown in Figure 3, with the decrease of specific humidity, the outlet temperature also decreases; that is, the heat transfer effect is better. With the increase of wind speed, the outlet temperature is lower. Under low specific humidity conditions, the outlet temperature decreases faster with the 
TABLe 2: Test time setting table.

\begin{tabular}{lccccc}
\hline Intake velocity $(\mathrm{m} / \mathrm{s})$ & 11.00 & 17.00 & 23.00 & 29.00 & $35.00(\mathrm{~min})$ \\
\hline Test time $(\mathrm{min})$ & $25 \operatorname{min~} 42 \mathrm{~s}$ & $16 \operatorname{min~} 36 \mathrm{~s}$ & $12 \operatorname{min~} 18 \mathrm{~s}$ & $9 \mathrm{~min} 42 \mathrm{~s}$ & 8 \\
\hline
\end{tabular}

increase of wind speed, and the overall trend is more significant, while under high specific humidity conditions, the outlet temperature changes more smoothly with wind speed.

When the fluid is turbulent in the pipe, the relationship between the factors and the surface heat transfer coefficient is as follows:

$$
h=f\left(u^{0.8}, \lambda^{0.6}, c_{p}^{0.4}, \rho^{0.8}, \mu^{0.4}, d^{-0.2}\right) .
$$

The higher the wind speed, the higher the heat transfer coefficient.

Using the lumped parameter method, the heat exchange between the heat conducting body and the fluid in the time interval from the initial time to a certain instant can be obtained by integrating the instantaneous heat flux with time, and the instantaneous heat flux of the heat conducting body is

$$
\varphi=-\rho c V \frac{d t}{d \tau}=-\rho c V\left(t_{0}-t_{\infty}\right)\left(-\frac{h A}{p c V}\right) \exp \left(-\frac{h A}{p c V} \tau\right)=\left(t_{0}-t_{\infty}\right) h A \exp \left(-\frac{h A}{p c V}\right)
$$

The total heat exchanged between $\tau=0$ and $\tau$ is

$$
Q_{\tau}=\int_{0}^{\tau} \varphi \mathrm{d} \tau=\left(t_{0}-t_{\infty}\right) \int_{0}^{\tau} h A \exp \left(-\frac{h A}{\rho c V} \tau\right) d \tau=\left(t_{0}-t_{\infty}\right) \rho c V\left[1-\exp \left(-\frac{h A}{\rho c V} \tau\right)\right]
$$

The higher the wind speed, the higher the heat transfer coefficient; from the above formula it can be seen that the amount of heat transfer and time have a direct relationship, when the outlet temperature is lower. However, the faster the wind speed, the less the heat transfer time in the condensing tube, and when the heat transfer decreases, the condensed water volume decreases. The outlet temperature decreases with the decrease of specific humidity. When the specific humidity is smaller, the heat transfer coefficient is higher, which is due to the reduction of specific humidity, the reduction of condensate water in the pipe, and the corresponding reduction of latent heat of water vapor phase transformation, resulting in the decrease of outlet temperature.

When the specific humidity is lower, with the increase of wind speed, the increase of heat transfer coefficient is more obvious, which is due to the increase of wind speed leading to the reduction of phase transformation in the condensation tube, and the lower the specific humidity is, the more obvious the reduction of phase transformation is. Insufficient to reasonably obtain the best operating conditions, using the central composite experimental design method, the nonlinear relationship between wind speed and humidity and the corresponding condensate water and outlet temperature is evaluated, the specific test design and results are shown in Table 3.

\subsection{Data Processing and Analysis of Central Composite Design} Test. The data of condensate water quantity and outlet temperature were obtained by central composite test, and the regression of multiple quadratic equation was carried out by response surface method, and the functions are fitted separately to obtain the corresponding mathematical models, then the corresponding mathematical model was obtained, and through variance analysis to judge the excellent degree of model fitting, the generated second-order model was as follows:

$$
y=\beta_{0}+\sum_{i=1}^{k} \beta_{i} x_{i}+\sum_{i=1}^{k} \beta_{i i} x_{i}^{2}+\sum_{i<j}^{k} \beta_{i j} x_{i} x_{j} .
$$

In the formula, $y$ is the objective function to be regressed, $K$ is the umber of variables, $\beta_{i}$ is the coefficient of Linear Parameter, $x_{i}$ is the factor variable, and $\beta_{i}$ is the quadratic parameter coefficient.

The mathematical model of the condensate water quantity and outlet temperature in the water intake experiment of the condenser with constant condensing temperature can be expressed by a quadratic equation in a unified form:

$$
y=\beta_{0}+\beta_{1}\left(v_{i}\right)+\beta_{2}\left(t_{i}\right)+\beta_{11}\left(v_{i}^{2}\right)+\beta_{22}\left(t_{i}^{2}\right)+\beta_{12}\left(v_{i} t_{i}\right) .
$$

The values of the coefficients in the formula are shown in Table 4.

The variance analysis of the model prediction data and the experimental data shows that the inlet wind speed and inlet specific humidity $P$ values are less than 0.01 , indicating that these two factors have a significant impact on the condensate water quantity and outlet temperature. 


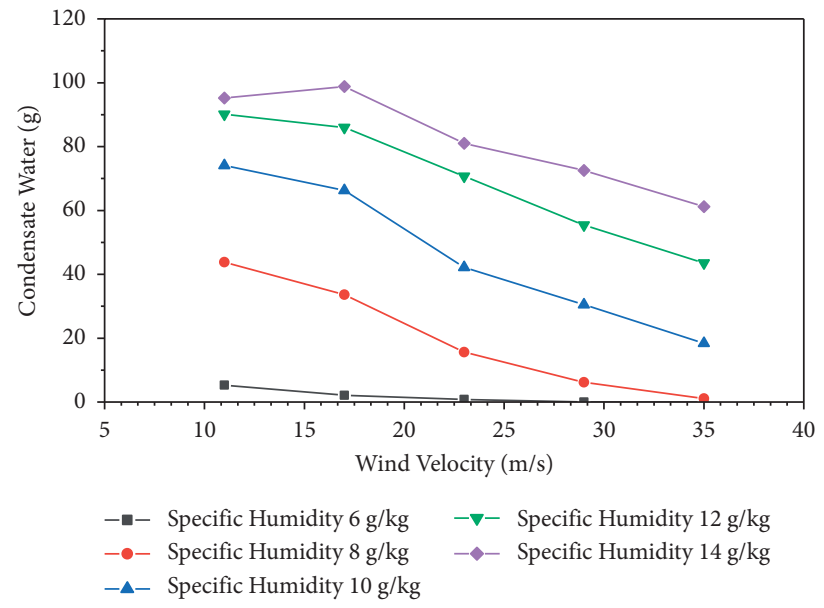

Figure 2: Variation of condensate water quantity under different wind speed and humidity.

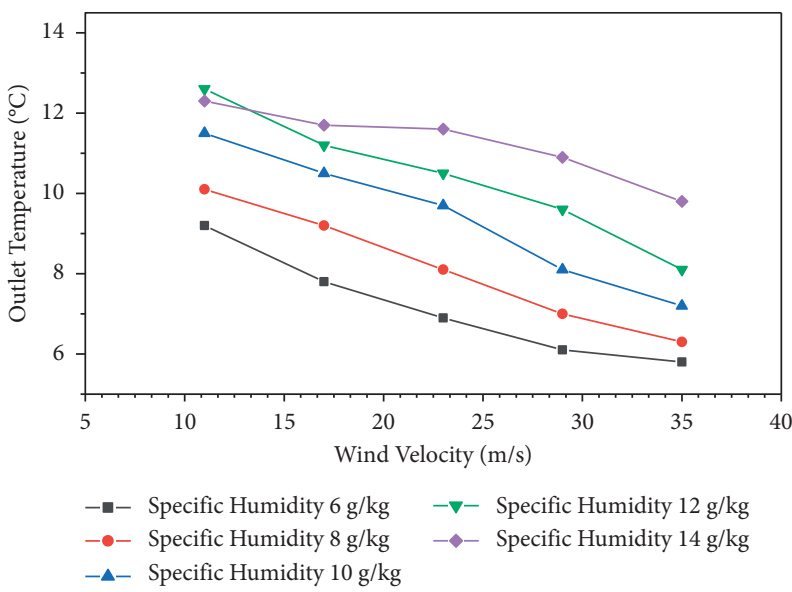

FIGURE 3: Variation of outlet temperature under different wind speed and humidity.

TABLE 3: Experiment and results of intensified condenser with variable air velocity.

\begin{tabular}{lccc}
\hline Air velocity vi $(\mathrm{m} / \mathrm{s})$ & Humidity ti $(\mathrm{g} / \mathrm{kg})$ & Condensate water Vw $(\mathrm{g})$ & Outlet temperature $T\left({ }^{\circ} \mathrm{C}\right)$ \\
\hline 35 & 14 & 61.2 & 8.7 \\
23 & 10 & 72.1 & 10 \\
23 & 10 & 72.1 & 10 \\
6.03 & 10 & 0 & 13 \\
23 & 10 & 72.1 & 10 \\
23 & 15.66 & 83.2 & 13 \\
11 & 14 & 95.2 & 12.3 \\
23 & 10 & 72.1 & 10 \\
39.97 & 10 & 40.5 & 7 \\
11 & 6 & 5.3 & 10 \\
23 & 4.34 & 0 & 8 \\
35 & 6 & 1.9 & 7 \\
23 & 10 & 72.1 & 10 \\
\hline
\end{tabular}

The response surface diagram of the amount of condensate water is analyzed, and the three-dimensional space curve of the amount of refrigeration condensate water, inlet wind speed, and inlet temperature is drawn. As shown in the figure, the relationship between the amount of condensation water and the two parameters can be seen intuitively.
From Figure 4, it can be seen that the effect of specific humidity on the amount of condensed water is significantly greater than that of wind speed, so according to different humidity conditions, the inlet wind speed of the condensing device has an optimal point, so according to the mathematical model, under the conditions of 
TABle 4: Condensate water model coefficient.

\begin{tabular}{lccccc}
\hline & & \multicolumn{2}{c}{ Coefficient } & $\beta_{11}$ & $\beta_{12}$ \\
\hline Model of condensate water & $\beta_{0}$ & $\beta_{1}$ & $\beta_{2}$ & -0.79 & -0.15 \\
Model of outlet temperature & -218.52 & 9.29 & 27.95 & -0.16 & 0 \\
\hline
\end{tabular}

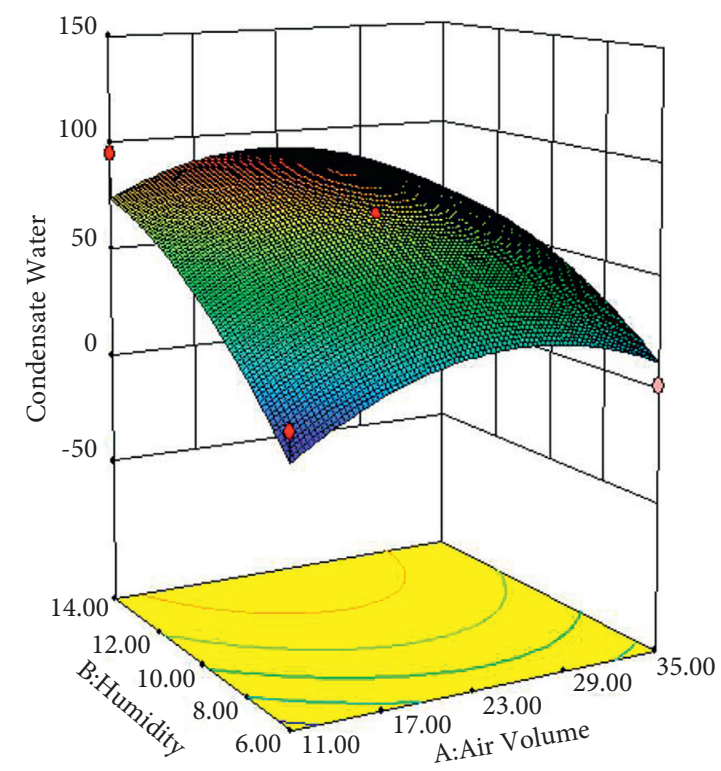

FIgURE 4: Response surface for $\mathrm{vw}=y(\mathrm{vi}, \mathrm{ti})$.

humidity ranging $6-14 \mathrm{~g} / \mathrm{kg}$, the optimal inlet wind speed range is $21.5 \mathrm{~m} / \mathrm{s}-24.5 \mathrm{~m} / \mathrm{s}$.

\section{Field Experiment}

Using the central composite experimental method, the relationship between wind speed and humidity and the corresponding condensate volume and outlet temperature is solved, and after deriving an expression for the nonlinear relationship between them, the field experimental system, experimental location, and experimental parameters are designed.

4.1. Experimental Principle. Due to the different specific heat capacity of air and soil, there is often a certain temperature difference. The soil temperature is often lower than the air temperature in the daytime, and the air temperature will gradually decrease after the higher temperature air is sent into the underground heat exchanger by the fan. When the air temperature drops to the dew point temperature, the excess moisture in the air will precipitate, and the purpose of water intake can be achieved by collection.

4.2. Experimental System. The process of the new type of cold air water intake system is shown in Figure 5. After being pressurized by the fan, the air enters the underground heat exchanger along the inlet pipeline and indirectly exchanges heat with the underground soil with lower temperature.
When the air temperature drops below the dew point temperature, the water vapor condenses and agglomerates to form liquid droplets, which are collected by the lower water reservoir along the heat exchanger pipeline and then pumped up by the water pump to complete a heat exchange cycle for utilization. The air after cooling is discharged to the ground with the outlet pipeline.

The model of the ground heat exchanger is shown in Figure 6. The cross-sectional area of the inlet and outlet is $0.01 \mathrm{~m}^{2}$, and a sensor is installed to monitor the local air temperature, humidity, wind pressure, and wind speed. A reducer tee is connected below the pipe of the heat exchanger, which mainly plays a role in separating air and condensate, and the condensate is collected by a water reservoir below the heat exchanger after separation. The diameter of the heat exchanger is $0.68 \mathrm{~m}$, the height is $0.98 \mathrm{~m}$, and it is placed vertically underground in the experiment, and the bottom is located at the position of $2 \mathrm{~m}$ underground.

4.3. Experimental Method and Main Parameters. Limited by the heat transfer area of the heat exchanger, the overall water intake rate of the experiment is not high, so in order to reduce the measurement error of water intake, a 20-hour continuous collection experiment was carried out, and the air flow rate remained unchanged during the experiment. In order to get better heat transfer effect, the experiment was carried out on a day when the air temperature was higher, 


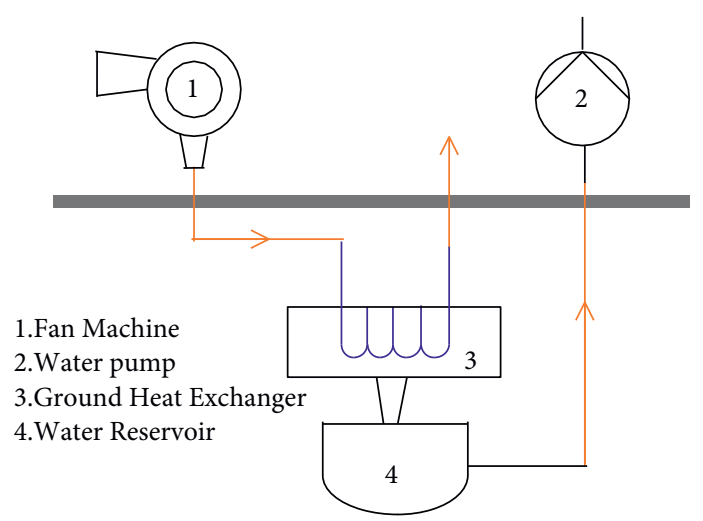

FIgURE 5: Technological flowchart of water intake by cold air.

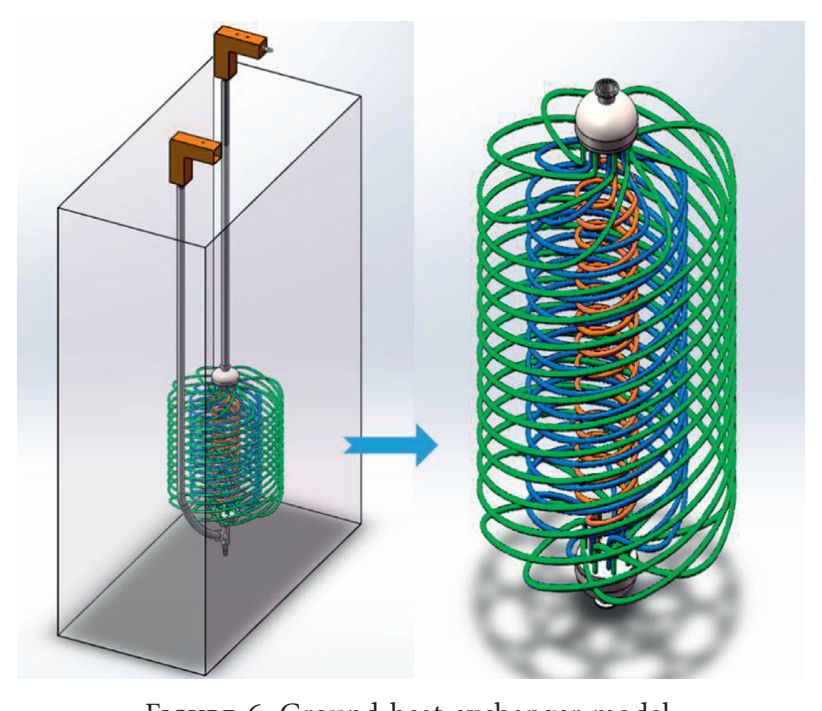

FIGURE 6: Ground heat exchanger model.

the air temperature was between $30^{\circ} \mathrm{C}$ and $45^{\circ} \mathrm{C}$, and the initial soil temperature was $19^{\circ} \mathrm{C}$; the temperature and humidity profile of the test reference city is shown in Figure 7.

The air inlet and outlet sensors were recorded every 2 minutes, and the soil temperature at a depth of $10 \mathrm{~cm}$ from the surface was also recorded. After the experiment, the condensed water collected from the water reservoir was weighed. The main experimental parameters are shown in Table 5.

\section{Results and Discussion}

5.1. Temperature Change during the Experiment. During the experiment, three sensors were used to monitor the air temperature of the air inlet and the air outlet and the soil temperature of $10 \mathrm{~cm}$ underground in real time, and a group of data was recorded every 2 minutes, and the temperature changes of the three positions in the whole experiment are shown in Figure 8. The results show that the overall heat transfer effect of air passing through the ground heat exchanger is ideal, and the outlet temperature is close to the soil temperature. The inlet air temperature fluctuates greatly with time, and the temperature difference is large in different time periods, while the soil temperature is relatively stable.
Therefore, the temperature difference between the inlet and outlet air is large in the daytime, the highest temperature can reach about $20^{\circ} \mathrm{C}$, and the effect of heat transfer between air and soil is better. At night, due to the low temperature of the outside air and the small temperature difference with the soil, the heat transfer effect is weakened.

During the experiment, soil temperature continued to rise slowly, after 20 hours, a total increase of $2.4^{\circ} \mathrm{C}$, and the temperature change was small. At the end of the experiment, the ventilation and heat transfer were stopped, and the soil temperature recovery was tested. The results showed that the soil temperature could recover to the initial state after about 24 hours, so the soil could be used as a continuous cold source to cool the air.

5.2. Humidity Changes during the Experiment. Inlet and outlet sensors can monitor the relative humidity changes before and after air heat transfer in real time, and the humidity change curve combined with real-time temperature is shown in Figure 9. During the experiment, the relative humidity of the atmosphere fluctuated from $20 \%$ to $50 \%$, and the calculated moisture content was $10-18 \mathrm{~g} / \mathrm{kg}$ dry air. The results show that, for different air initial relative 


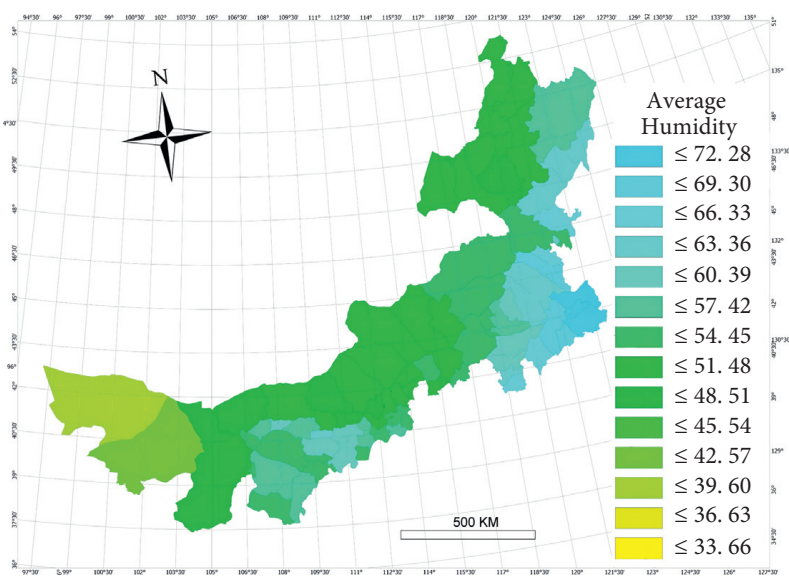

(a)

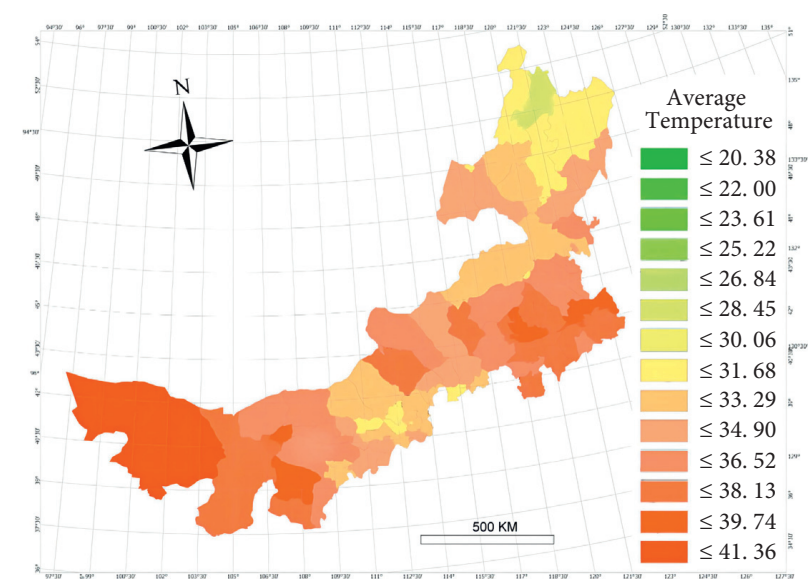

(b)

Figure 7: The temperature and humidity profile. (a) The humidity profile. (b) The temperature profile.

TABLE 5: Main parameters of cold air water intake experiment.

\begin{tabular}{lc}
\hline Main parameters & $13: 20-9: 00$ \\
\hline Data collection time & 2.3738 \\
Heat exchange area $\left(\mathrm{m}^{2}\right)$ & 19 \\
Soil initial temperature $\left({ }^{\circ} \mathrm{C}\right)$ & $30-45$ \\
Air temperature $\left({ }^{\circ} \mathrm{C}\right)$ & $1.5 \pm 0.1$ \\
Air velocity $(\mathrm{m} / \mathrm{s})$ & $54 \pm 3.5$ \\
Air flow $\left(\mathrm{m}^{3} / \mathrm{h}\right)$ & $20-50$ \\
Air relative humidity $(\%)$ & 1.2 \\
Intake pressure $(\mathrm{KPa})$ & 0.1 \\
Outlet pressure $(\mathrm{KPa})$ & \\
\end{tabular}

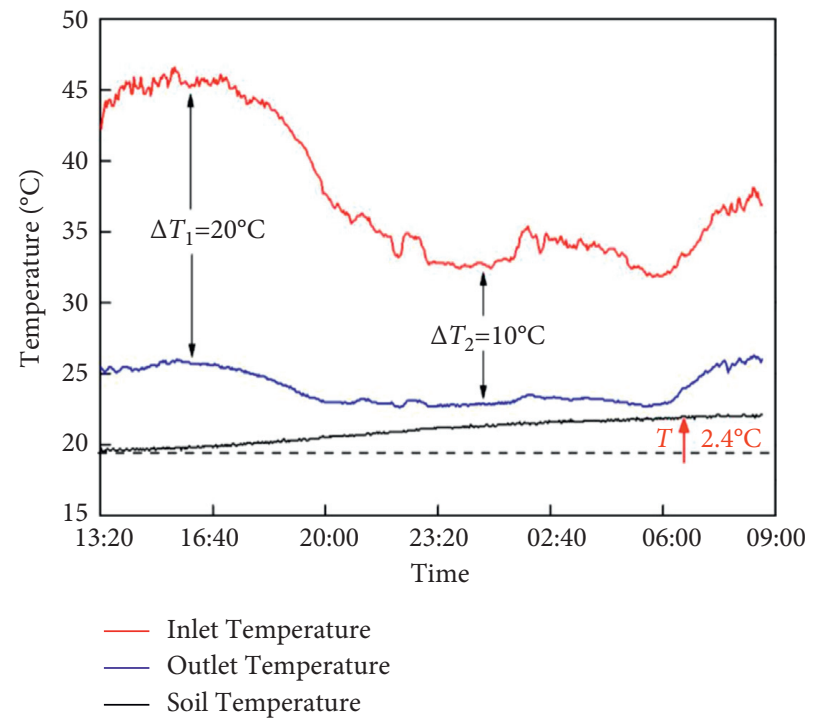

FIgURE 8: Temperature change curve at different detection positions.

humidity, the air humidity of inlet and outlet always keep synchronous, and no matter whether the air humidity is high or low, the cold air water intake system can obtain more stable water intake.
5.3. Analysis of Influencing Factors of Water Intake Capacity. The instantaneous water intake obtained by theoretical calculation is shown in Figure 10. With the progress of the experiment, the instantaneous water output of air cooling 


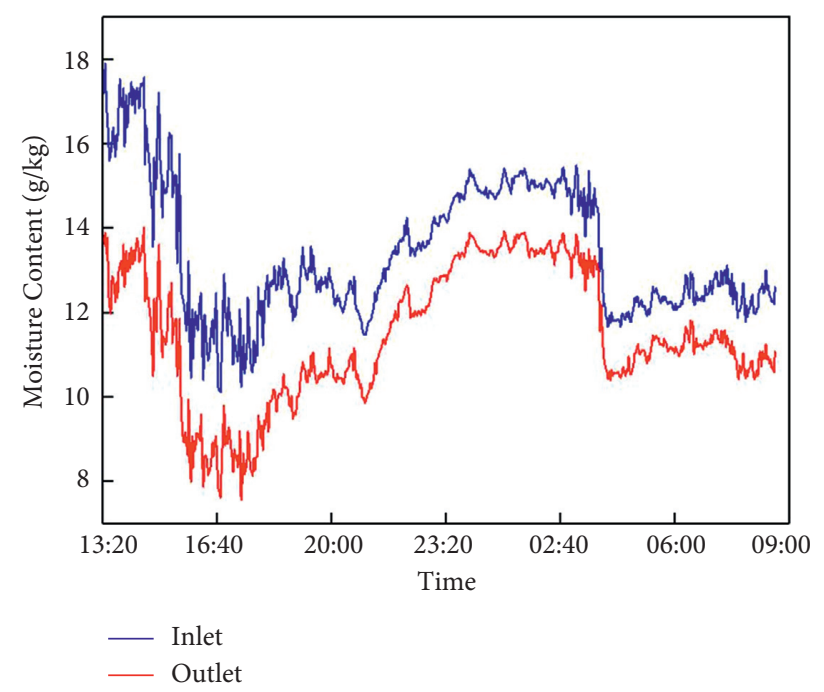

FIgURE 9: Air humidity in inlet and outlet.

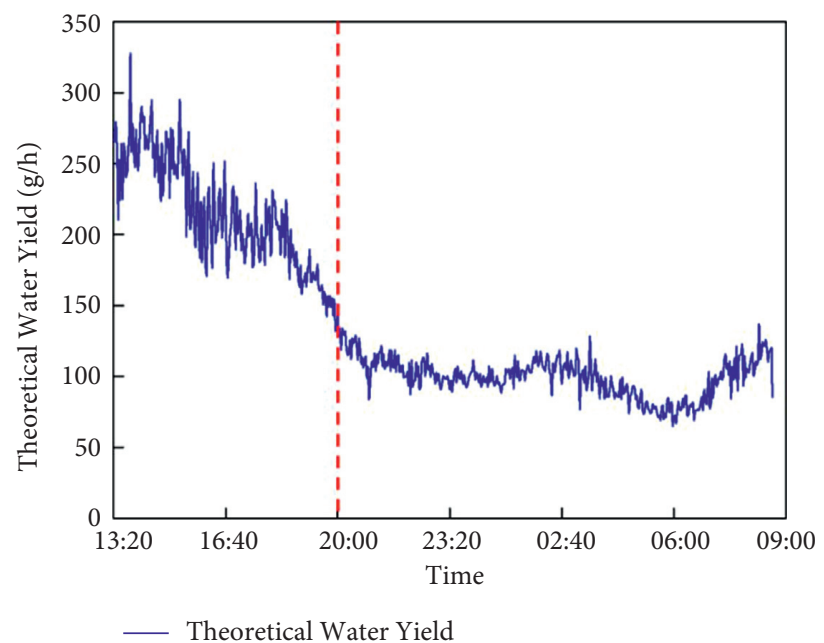

Figure 10: Theoretical water yield of air cooling.

gradually decreased and tended to be stable. The results show that the small water intake experimental equipment can theoretically take 100-300 g water from air per hour, and the theoretical water intake can reach $2.7 \mathrm{~kg}$ in 20-hour continuous collection experiment, while the actual weighing result is $2.2 \mathrm{~kg}$, with a relative error of $18 \%$.

The possible causes of the error are analyzed. On the one hand, the actual condensation amount is less than the theoretical value because of the supersaturation of water vapor in the process of condensation. On the other hand, it may be due to the fact that part of the condensate water is attached to the inner wall of the pipeline and the water reservoir during the extraction process, resulting in the actual measurement value being too small. At the same time, the results show that it is very effective to use ground air to cool the water.

In addition, in a fixed period of time, the soil temperature is relatively constant, and the water intake capacity of the system is mainly affected by air temperature; the greater the temperature difference between air and soil, the stronger the water intake capacity of the system. The water intake is less affected by the relative humidity of the air, which shows that the environmental adaptability of the system is relatively strong, and it can also be used to obtain more stable water sources in extremely arid areas.

\section{Conclusions}

The availability of water resources is becoming increasingly problematic, and the natural reserves are gradually reducing. This work proposes a new simple and innovative method of drawing water from the air, based on extracting water from air process achieved by using the soil as the cold source.

Through the central composite design experiment, the condensate water quantity and outlet temperature under different wind speed and humidity conditions were analyzed, and the mathematical model equation expression of condensate water quantity and outlet temperature was 
obtained. According to the mathematical model and experimental environment, after analyzing the influence of each parameter on the experiment, the experimental parameters were set and the experiment was carried out. The results showed the following:

(1) The mathematical model of condensate water quantity and outlet temperature can be expressed by a quadratic equation in a unified form:

$$
y=\beta_{0}+\beta_{1}\left(v_{i}\right)+\beta_{2}\left(t_{i}\right)+\beta_{11}\left(v_{i}^{2}\right)+\beta_{22}\left(t_{i}^{2}\right)+\beta_{12}\left(v_{i} t_{i}\right) .
$$

(2) Air through the underground heat exchanger heat transfer effect is ideal, and the water intake can reach $2.2 \mathrm{~kg}$ in 20-hour continuous collection experiment. For different inlet air temperature, outlet temperature is always close to the soil temperature. In the whole process, the soil temperature changed slightly and recovered rapidly in a short time, which confirmed the feasibility of soil as a cold source for air condensation.

(3) Through the comparative analysis of the results and the causes of the relative experimental errors and the conclusion that the field test and laboratory test results are basically consistent, the experiment confirms the correctness of the theoretical model and provides a theoretical basis for future water intake tests.

\section{Abbreviations}

A: Cross-sectional area $\left(\mathrm{m}^{2}\right)$

C: Specific heat capacity

$C_{p}$ : Constant pressure specific heat

$d_{i}$ : Inner diameter of pipe

$e$ : Protrusion height

$h$ : Heat exchange condition

L: Characteristic size of flow field

$P$ : $\quad$ Pitch distance

Pr: Prandtl number

q: Heat exchange heat flux density

Q: Total heat

Re: Reynolds number

$T_{m}$ : Average temperature of fluid and wall

$u: \quad$ Velocity $\left(\mathrm{m} \cdot \mathrm{s}^{-1}\right)$

$\rho$ : Density

$\mu$ : Medium viscosity

$\Phi:$ Instantaneous heat flow

$\lambda: \quad$ Fluid thermal conductivity

$\tau$ : Time constant.

\section{Data Availability}

All data, models, and code generated or used during the study appear in the article.

\section{Conflicts of Interest}

The authors declare that they have no conflicts of interest.

\section{Acknowledgments}

This work was supported in part by the Intergovernmental International Science and Technology Innovation Cooperation Key Projects (Grant no. 2018YFE0196000) and the China Institute of Water Resources and Hydropower Research (MK2018J09).

\section{References}

[1] G. Q. Wang, J. Y. Zhang, and S. L. Zhang, "Impacts of climate change on water resources and its vulnerability in China," Journal of Water Resources and Water Engineering, vol. 16, no. 2, pp. 7-10, 2005.

[2] D. Molden, Ed., Water for Food Water for Life: A Comprehensive Assessment of Water Management in Agriculture, Earthscan, London, UK, 1st edition, 2007.

[3] WHO/UNICEF, Progress on Sanitation and Drinking Water 2015 Update and MDG Assessment, Geneva, Switzerland, 2015, https://www.who.int/water_sanitation_health/ publications/jmp-2015-update/en.

[4] Z. Lingyu and L. Yongkui, "A preliminary analysis of the waterscape in face of the shortage of water," Procedia Engineering, vol. 21, no. none, pp. 693-699, 2011.

[5] A. M. Hamed, "Absorption-regeneration cycle for production of water from air-theoretical approach," Renewable Energy, vol. 19, no. 4, pp. 625-635, 2000.

[6] A. M. Hamed, A. E. Kabeel, and E. S. B. Zeidan, "A technical review on the extraction of water from atmospheric air in arid zones," JP Journal of Heat and Mass Transfer, vol. 4, no. 3, pp. 213-228, 2010.

[7] V. E. Obrezkova, Hydro-energy, Energoatomezdat, Moscow, Russia, 1988.

[8] A. . Khalil, "Dehumidification of atmospheric air as a potential source of fresh water in the UAE]," Desalination, vol. 93, no. 1-3, pp. 587-596, 1993.

[9] R. X. Zhang, R. Q. Zang, and J. X. Liu, "Study on properties of water extraction from cooled air system under all operating conditions," Cryogenics and Superconductivity, vol. 44, no. 01, pp. 51-55, 2016.

[10] J. Y. Wang, R. Z. Wang, Y. D. Tu, and L. W. Wang, "Universal scalable sorption-based atmosphere water harvesting," Energy, vol. 165, pp. 387-395, 2018.

[11] M. Cao, J. Xiao, C. Yu, K. Li, and L. Jiang, "Hydrophobic/ hydrophilic cooperative janus system for enhancement of fog collection," Small, vol. 11, no. 34, pp. 4379-4384, 2015.

[12] H. I. Abualhamayel and P. Gandhidasan, "A method of obtaining fresh water from the humid atmosphere," Desalination, vol. 113, pp. 5-63, 1997.

[13] A. M. Hamed, "Theoretical and experimental study on the transient adsorption characteristics of a vertical packed porous bed," Renewable Energy, vol. 27, no. 4, pp. 525-541, 2002.

[14] SunToWater Technologies LLC, Make Your Own Water, SunToWater Technologies, LLC, California, CA, USA, 2020.

[15] Aqua Sciences Inc, Water from the AIR Virtually Anywhere, Aqua Sciences, Inc., New York, NY, USA, 2020.

[16] M. Eslami, F. Tajeddini, and N. Etaati, "Thermal analysis and optimization of a system for water harvesting from humid air using thermoelectric coolers," Energy Conversion and Management, vol. 174, no. OCT, pp. 417-429, 2018.

[17] K. Pontious, B. Weidner, and N. Guerin, "Design of an atmospheric water generator: Harvesting water out of thin air," in Proceedings of the Systems \& Information Engineering Design Symposium, pp. 6-11, IEEE, April 2016. 
[18] F. Zohra and B. Asiabanpour, "Design and development of an integrated water system combining rainwater harvesting system (rhs) and atmospheric water generator (awg)," Thesis, Texas State University, Texas, TX, USA, 2020.

[19] Y. A. Çengel and A. J. Ghajar, Heat and Mass Transfer: Fundamentals \& Applications, McGraw-Hill, New York, NY, USA, 4th edition, 2011.

[20] A. Habiyaremye, "Water innovation in South Africa: mapping innovation successes and diffusion constraints," Environmental Science \& Policy, vol. 114, pp. 217-229, 2020.

[21] P. M. Congedo, C. Baglivo, and G. Negro, "A new device hypothesis for water extraction from air and basic air condition system in developing countries," Energies, vol. 14, no. 15, p. 4507, 2021.

[22] A. Freni, G. Maggio, A. Sapienza, A. Frazzica, G. Restuccia, and S. Vasta, "Comparative analysis of promising adsorbent/ adsorbate pairs for adsorptive heat pumping, air conditioning and refrigeration," Applied Thermal Engineering, vol. 104, pp. 85-95, 2016.

[23] D. Croce, F. Giuliano, M. Bonomolo, G. Leone, R. Musca, and I. Tinnirello, "A decentralized load control architecture for smart energy consumption in small islands," Sustainable Cities and Society, vol. 53, Article ID 101902, 2020.

[24] J. Lindblom and B. Nordell, "Water production by underground condensation of humid air," Desalination, vol. 189, no. 1-3, pp. 248-260, 2006.

[25] D. Mazzeo, N. Matera, P. De Luca, C. Baglivo, P. M. Congedo, and G. Oliveti, "A literature review and statistical analysis of photovoltaic-wind hybrid renewable system research by considering the most relevant 550 articles: an upgradable matrix literature database," Journal of Cleaner Production, vol. 295, Article ID 126070, 2021. 